\title{
TOXOPLASMA REACTIVATION AFTER RENAL TRANSPLANT - LOW EXPRESSION OF NITRIC OXIDE SYNTHASE AND A TH2 PATTERN OF IMMUNE RESPONSE
}

\section{REATIVAÇÃO DE TOXOPLASMA APÓS TRANSPLANTE RENAL - BAIXA EXPRESSÃO DE OXIDO NITTRICO SINTETASE E PADRÃO DE RESPOSTA IMUNE TH2}

Felipe Francisco Tuon ${ }^{1}$, Daiane Maria Cordeiro²

\begin{abstract}
RESUMO
Introdução: Apesar de o mecanismo de imunossupressão associada com a reativação de toxoplasmose em pacientes transplantados ser conhecido, a interação entre células humanas e citocinas não está bem estabelecida. Relato: Descrevemos um caso de reativação de toxoplasmose em um paciente transplantado renal com pneumonite. A expressão das citocinas e os fenótipos celulares foram avaliados neste caso. Resultados: Houve um predomínio do padrão de resposta immune Th2, com forte expressão de TGF-beta, TNF-alfa e IL-10. A expressão do receptor de IL-2, oxido nítrico sintetase e IFNgama foi fraca. Conclusão: A reativação de toxoplamose no pulmão foi associada a um padrão de resposta imune Th2 e atividade macrofágica diminuída.
\end{abstract}

Palavras-chave: Toxoplasmose. Toxoplasma gondii. Transplante renal. Resposta imune.

\begin{abstract}
Background: The mechanism of immunosuppression associated with reactivation of the toxoplasmosis in transplanted patients is known, but the interactions of the human cells and cytokines expression is not well established. Case report: We described a case of toxoplasmosis reactivation in a renal transplanted patient with pneumonitis. The in situ expression of cytokines and cellular phenotypes was evaluated in this case. Results: A Th2 pattern of immune response predominated with strong expression of TGF-beta, TNF-alpha and IL-10. The expression of IL-2 receptor, nitric oxide synthase and IFN-gamma were weak. Conclusion: The reactivation of toxoplasmosis in the lung was associated with a Th2 pattern of immune response and decreased activity of macrophages.
\end{abstract}

Keywords: Toxoplasmosis. Toxoplasma gondii. Kidney transplantation. Immune response.

1 - Division of Infectious Diseases, Hospital de Clínicas da Universidade Federal do Paraná, Curitiba, Paraná, Brazil.

2 - Faculdade Evangelica de Medicina do Paraná, Curitiba, Paraná, Brazil.

Contato do Autor / Mail to:

Felipe Francisco Tuon - flptuon@gmail.com

Infectious and Parasitic Diseases Clinic, Hospital Universitário Evangélico de Curitiba, Alameda Augusto Stellfeld 1908, $3^{\circ}$. andar - SCIH - Bigorrilho, CEP number 80730-150, Curitiba, Brazil. 


\section{Introduction}

Post-transplant toxoplasmosis is frequently described in heart transplanted patients, but reactivation in renal transplanted patients is less common 1,2 . Reactivation is the most common cause of the disease in this group of patients, although de novo infection can occurs. The attributed mortality is high and more than 50\% of toxoplasmosis reactivation in renal transplantation recipients are diagnosed at autopsy ${ }^{1}$.

Pneumonia is the second most common manifestation of the reactivation, after toxoplasmic encephalitis, and both clinical forms occur due to immunosuppressive drugs. The mechanism of action of these drugs is well understood, but the immune response pattern found in the human lung tissue during Toxoplama gondii reactivation was not studied. A previous in vitro study showed that reactivation of $T$. gondii infection in lungs results from a decrease in Th1 cytokine levels or a transient increase in Th2 cytokine levels ${ }^{1}$.

The aim of this report is to describe a case of $T$. gondii pneumonia in a renal transplanted patient and evaluate the adaptative and innate immune aspects found in the lung tissue.

\section{Case report}

A 66-year-old male patient with chronic renal failure secondary to nephrolitiasis was admitted asymptomatic for renal transplantation from cadaver donor. Patient and donor tests were positive for Toxoplasma and cytomegalovirus (ELISA IgG positive and IgM negative). Serology of hepatitis (A, B and C), syphilis, HIV, Chagas and HTLV were all negative from both. The patient received antithymocyte globulin (ATG) for ten days and methylprednisolone 500mg for induction therapy, followed by daily tacrolimus, prednisone and mycophenolate mofetil. Gancyclovir was used for cytomegalovirus prophylaxis and sulphametoxazol/trimetoprim for toxoplasmosis toxoplasmosis since the day of the transplant. In the 20th day after transplantation, the patient had fever and cough followed by myalgia and dyspnea two days later. One week after initial symptoms, the dyspnea progressed to acute respiratory failure with severe hypoxemia and death overcome despite intensive care. Chest roentgenographs were normal when symptoms initiated but diffuse bilateral interstitial infiltrates were present in the last day. Blood, urine and sputum culture were negatives. An autopsy was performed.

In the histopathological exam, Toxoplasma bradyzoites were found in central nervous system without inflammatory infiltrate, which is compatible with absence of encephalitis. Interstitial pneumonia with septal thickness and mononuclear infiltrate were found associated with parenchymal necrosis. In these areas, several tachyzoites of Toxoplasma were identified by immunohistochemistry method. The section was incubated with an anti-T. gondii antibody produced in mouse (kindly provided by Instituto de Medicina Tropical de São Paulo), diluted 1:400 in albumin solution, over-night at $4^{\circ} \mathrm{C}$. Incubations with biotinylated anti-mouse antibody and with streptavidinbiotin-peroxidase complex (Dako, LSAB, Glostrup Denmark) were carried out for $30 \mathrm{~min}$ at $37^{\circ} \mathrm{C}$. The sections were counterstained with Mayer-Hematoxylin.

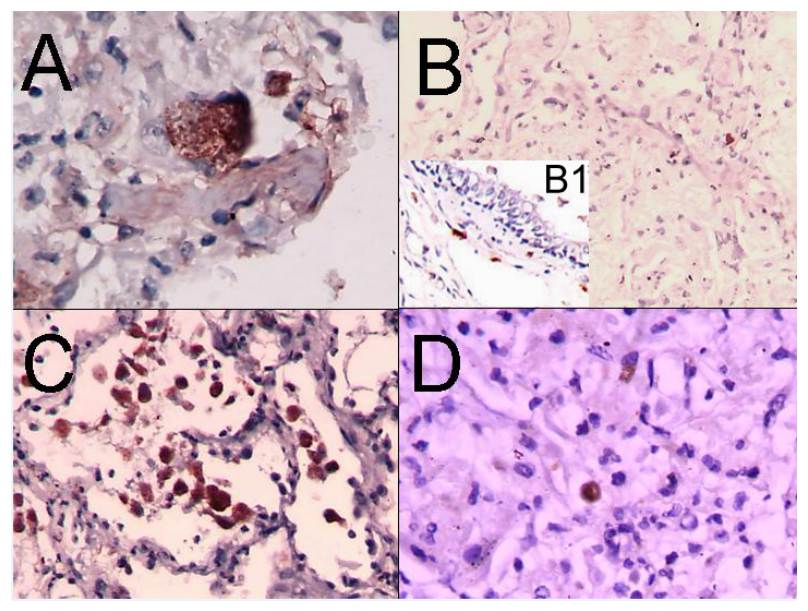

Figure 1. In situ evaluation of cytokines and cellular phenotypes in toxoplasma pneumonia through immunohistochemistry in lung tissue (400x) counterstained with Mayer-Hematoxylin. Phenotypes cellular compared with normal lung. A) presence of antigens to Toxoplasma gondii in the lung tissue rounded by an acute inflammatory infiltrate with septal thickness; B) low expression of CD4+ lymphocytes compared with control (B1); C) alveolar macrophages infiltrate in toxoplasma pneumonia; D) low expression of iNOS by the interstitial macrophages.

In situ immune response was studied through cytokines analysis and immunohistochemical study for phenotype markers. The paraffin-embedded lungs were resectioned and $5 \mu \mathrm{m}$ sections were adhered to sylane treated slides. Sections were submitted to hematoxylineosin (HE) stain and immunohistochemistry with monoclonal antibodies revealed by the streptavidin-biotin peroxidase method, using endogenous biotin blocking system (DAKO, USA) with modifications as elsewhere described $^{3}$. The following monoclonal antibodies for cellular phenotypes and cytokines were used in this process: CD4 (M834/DAKO, Glostrup Denmark), CD8 (M7103/DAKO, Glostrup Denmark), CD20 (M755/DAKO, Glostrup Denmark), CD68 (M786/DAKO, Glostrup Denmark), NK (M1014/DAKO, Glostrup Denmark), IL-2r (M731/DAKO, Glostrup Denmark), IL-4 (AB204/R\&D Systems, Minneapolis, USA), IL-10 (MAB 217/ R\&D Systems, Minneapolis, USA), IL-12 (MAB 219/R\&D 
Systems, Minneapolis, USA), TNF- $\beta$ (IP300/Genzyme, Boston, USA), and IFN-y (IP 500/Genzyme, Boston, USA). Macrophage activation was determined by evaluation of NOS activity using inducible rabbit polyclonal Antibody antinitric oxide synthase (NOS) (PAB 482728/Calbiochem, Darmstadt, Germany). This case was compared with a control group of normal lungs described elsewhere, using semi-quantitative method 4 .

In situ immune pattern of response showed an increased $\mathrm{CD} 8 / \mathrm{CD} 4$ ratio although both were globally decreased in comparison with other cells (figure 1). There were a large number of intra-alveolar and intra-septal macrophages (CD68+). Rare CD20+ cells (B cell lymphocytes) and NK cells were present in the tissue. The expression of cytokine such as TGF- $\beta$, TNF- $\alpha$ and IL-10 was increased in extracellular tissue and in macrophages, mainly around Toxoplasma cysts. IFN- $\gamma$, iNOS and IL-4 showed weak in situ expression. IL-2r expression was undetectable.

\section{Discussion}

Toxoplasmosis reactivation was formerly described in a renal transplanted patient in 1966 and represents a severe unrecognized opportunistic infection with high mortality 1 . Two forms of the same $T$. gondii can be present in humans: active tachyzoite and dormant form of bradyzoite 5 . The tachyzoite stage is responsible for active infection and expresses antigens that induce a Th1 pattern of immune response. If inflammatory response is adequated, $T$. gondii differentiates into dormant forms, the bradyzoites. The bradyzoites are present as tissue cysts in the brain, retina, lung and other organ for all life of the host. The maintenance of the tissue cysts with bradyzoites occurs due to adequate and continuous IFN-y production and further nitric oxide by activated macrophages, which favors transformation of active tachyzoites to bradyzoites 6 . IFN-y is produced by $\mathrm{CD} 8+$ lymphocytes, which are activated by CD4+ lymphocytes through IL-2 production. Although other cells also produces IFN- $\gamma$, as dendritic cells, natural killer cells and CD4+ lymphocytes. Any disruption of this cascade can interfere with IFN-y synthesis and loss of bradyzoites control7. When low levels of IFN-y are present in the tissue, transformation of bradyzoites to tachyzoites occurs, allowing replication of this fast-growing forms and further disease reactivation.

Lung reactivation of toxoplasmosis is clinically expressed after the "wake up" of dormant bradyzoites from the own pulmonary tissue or, more commonly, as a shock organ within the first week of intense parasitaemia of tachyzoites from central nervous system migrating to the lung.
We showed, in the case here reported, increased expression of TGF- $\beta$, TNF- $\gamma$ and IL-10 with weak expression of IL-2 $r$ and IFN- $y$ in the lung tissue. This pattern of cytokines is the ideal representation of inflammatory pattern of Th2 response ${ }^{8}$. Low levels of IL- $2 r$ decreases IFN-y production by $\mathrm{CD} 8+$ lymphocytes. The inhibition of IFN-y does not activate macrophages, allowing tachyzoite multiplication ${ }^{9}$. In animal models, the reactivation of the disease is associated with decreased levels of tissue IFN-Y and IL-2r with increased levels of interleukin-10 (IL-10) as seen in our case ${ }^{10}$.

We demonstrated the presence of large number of macrophages without expression of NOS (non-activated macrophage). The IFN-y induces NOS which yield nitric oxide and further destruction of phagocyted tachyzoites. This pattern of immune response found in the lung allowed tachyzoite tissue invasion and intense necrosis with the organ failure. $\mathrm{CD} 4+$ and $\mathrm{CD} 8+$ lymphocytes were decreased in lung tissue, which could be related with low levels of IFN-y, IL-2 and iNOS. The number of macrophages increased, but not activated (low iNOS levels). Intense necrosis with increased number of macrophages was found in this case. Gazzinelli et al. showed a similar pattern of iNOS but with increased levels of Th1 cytokines ${ }^{11}$.

Those immunological disorders were caused by the immunosuppressive drugs. A previous study evaluated the effect antithymocyte globulin on experimental toxoplasmosis in mice to get further information about the immune mechanisms important in reactivation of toxoplasmosis ${ }^{12}$. The results suggested that treatment with ATG may activate a latent Toxoplasma infection and aggravate the course of the disease. The decrease of lymphocytes CD4+ and CD8+ in the lung tissue of our case is compatible with the previous ATG use and the increased number of inactivated macrophage with prednisone use.

Tacrolimus is a calcineurin inhibitor and decreases the expression of IL-2 by lymphocytes ${ }^{13}$. The presence of tachyzoites in the tissue also decreases the calcium entry into lymphocytes, decreasing the activity of calcineurin and IL-2 synthesis ${ }^{14}$ Another immunosuppressive drug used by our patient, mycophenolate mofetil, inhibits inosine-monophosphate dehydrogenase enzyme present in lymphocytes, which is important in the synthesis of nucleic acids. Although mycophenolate can corroborate to toxoplasmosis reactivation, it also inhibits the enzyme present in the parasite, decreasing the replication of the tachyzoites ${ }^{15}$.

\section{Conclusion}

Several aspects of the immune response were explored in this case. We could expand some of the findings herein described to other situations in renal transplant and opportunistic infections. In situ study of 
immune response by immunohistochemistry is a tool for the understanding of the immunopathology of a wide variety of infectious diseases, including toxoplasmosis. It permits the detection of the types of cells and cytokines involved in the inflammatory in situ tissue response, which cannot be real using serum inflammatory markers.

In summary, the reactivation of toxoplasmosis in transplanted patients is a serious unrecognized disease due to difficult diagnosis and can be explained by the immunosuppressive therapy. The immune condition associated with this disorder is probably a Th2 pattern of response with increased levels of TGF- $\beta$ and IL-10 with low expression of IL-2 $r$ and low levels of IFN- $\gamma$ that are expressed by an increased number of inactivated macrophages in the lung tissue producing parenchymal necrosis. The increased expression of TNF- $\beta$ suggests maintenance of innate immune response.

\section{Acknowledgements}

The present work benefited from the support by RA Brasil, ER Fernandes and MI Duarte from the Laboratory of Pathology of Transmissible Diseases from the Medical School of University of Sao Paulo and MA Shikanai-Yasuda from the Laboratory of Immunology (LIM 48) of Hospital das Clínicas and Department of Infectious and Parasitic Diseases from the Medical School of University of Sao Paulo.

\section{References}

1. Derouin F, Debure A, Godeaut E, Lariviere M, Kreis $\mathrm{H}$. Toxoplasma antibody titers in renal transplant recipients. Pretransplant evaluation and posttransplant follow-up of 73 patients. Transplantation 1987; 44:515-8.

2. Wulf MW, van CR, Portier R, et al. Toxoplasmosis after renal transplantation: implications of a missed diagnosis. J Clin Microbiol 2005; 43:3544-7.

3. Tuon FF, Guedes F, Fernandes ER, Pagliari C, Amato VS, Seixas Duarte MI. In situ immune responses to interstitial pneumonitis in human visceral leishmaniasis. Parasite Immunol 2009; 31:98-103.

4. Moussallem TM, Guedes F, Fernandes ER, et al. Lung involvement in childhood measles: severe immune dysfunction revealed by quantitative immunohistochemistry. Hum Pathol 2007; 38:123947.

5. Denkers EY, Gazzinelli RT. Regulation and function of T-cell-mediated immunity during Toxoplasma gondii infection. Clin Microbiol Rev 1998; 11:569-88.
6. Hayashi S, Chan CC, Gazzinelli R, Roberge FG. Contribution of nitric oxide to the host parasite equilibrium in toxoplasmosis. J Immunol 1996; 156:1476-81.

7. Barcan LA, Dallurzo ML, Clara LO, et al. Toxoplasma gondii pneumonia in liver transplantation: survival after a severe case of reactivation. Transpl Infect Dis 2002; 4:93-6.

8. Liu YJ. TSLP in epithelial cell and dendritic cell cross talk. Adv Immunol 2009; 101:1-25.

9. Gazzinelli RT, Wysocka M, Hayashi S, et al. Parasiteinduced IL-12 stimulates early IFN-gamma synthesis and resistance during acute infection with Toxoplasma gondii. J Immunol 1994; 153:2533-43.

10. Filice GA, Clabots CR, Riciputi PE, Goni-Laguardia O, Pomeroy C. Changes in cytokine levels during reactivation of Toxoplasma gondii infection in lungs. Infect Immun 1999; 67:2082-9.

11. Gazzinelli RT, Eltoum I, Wynn TA, Sher A. Acute cerebral toxoplasmosis is induced by in vivo neutralization of TNF-alpha and correlates with the down-regulated expression of inducible nitric oxide synthase and other markers of macrophage activation. J Immunol 1993; 151:3672-81.

12. Strannegard O, Lycke E. Effect of antithymocyte serum on experimental toxoplasmosis in mice. Infect Immun 1972; 5:769-74.

13. Almawi WY, Melemedjian OK. Clinical and mechanistic differences between FK506 (tacrolimus) and cyclosporin A. Nephrol Dial Transplant 2000; 15:19168.

14. Haque S, Dumon H, Haque A, Kasper LH. Alteration of intracellular calcium flux and impairment of nuclear factor-AT translocation in $T$ cells during acute Toxoplasma gondii infection in mice. J Immunol 1998; 161:6812-8.

15. Sullivan WJ, Jr., Dixon SE, Li C, Striepen B, Queener SF. IMP dehydrogenase from the protozoan parasite Toxoplasma gondii. Antimicrob Agents Chemother 2005; 49:2172-9. 